\title{
WALL STATIC PRESSURE DISTRIBUTION DUE TO CONFINED IMPINGING CIRCULAR AIR JET
}

\author{
Patil Deogonda ${ }^{1}$, Vijaykumar N Chalwa ${ }^{2}$, Murugesh M.C ${ }^{3}$, Vinod Dixit ${ }^{4}$ \\ 1Assistance Professor, Dept of Mechanical Engineering. SMSMPITR, Akluj \\ ${ }^{2}$ Dean R\&D, Dept. of Mechanical Engineering, SMSMPITR, Akluj \\ ${ }^{3}$ Assistance professor, Dept. of Mechanical Engineering. G.M.I.T, Davangere \\ ${ }^{4}$ Design engineer Zuti Engg. Pvt.Ltd. Hyderabad
}

The wall static pressure of confined air jet, impinging normally onto a flat plate has been experimentally investigated. The mean velocities, and wall static pressures were measured for Reynolds numbers ranging from 18,000 to 40,000 and the nozzle-to-plate spacing's in range of 0.25-4. The effects of Reynolds number, nozzle-to-plate spacing and flow confinement on the pressure coefficient are reported. The pressure distributions are independent of the Reynolds number and depend on nozzle-to-plate spacing only. The maximum pressure occurs at the stagnation point $(r / d=0)$ for the all nozzle-to-plate spacing's studied and as $r / d$ increases, the pressure decreases. At very low spacing $(z / d=0.25)$ stagnation pressure is rather larger than those of the other spacing's due to rapidly decreasing of axial velocity in the deflection zone. It is concluded that a sub atmospheric region occurs on the impingement plate for the nozzle-to-plate spacing's up to one for all the Reynolds number; however, there is no evidence of the sub atmospheric region in confined jet For the nozzle-to-plate spacing's greater than one.

\section{INTRODUCTION}

Impinging jets are used in many industrial applications to achieve enhanced coefficients for convective heating, cooling or drying. Applications include tempering of glass plate, annealing of metal sheets, drying of textile and paper products, deicing of aircraft systems and cooling of heated components in gas turbine engines, Computers and electronic instruments. The flow and heat transfer characteristics of an impinging jet are affected from a number of parameters such as the nozzle geometry, the nozzle-to-plate spacing (H/D), and Reynolds number.

The impinging jets can be classified by their boundary as confined flow field. Confined geometry, where the radial spread of the jet is bounded by a confinement plate, has been investigated extensively in literature due to its importance in industrial applications.

\subsection{Structure of Free Jet}

The structure of free jet is as shown in the Fig. 1.a. The three zones of the free jet are

a) Potential core zone

b) Developing zone

c) Developed zone

The jet immediately leaving the nozzle comes in contact with surrounding stagnant air. The free shearing between moving jet and stagnant air causes the mixing due to which fluid particles of the surrounding air are carried with the jet, which causes the sharing of the momentum of the jet and formation of the shear layer. Within the shear layer there exists a flow of jet which is still unaffected by mixing and its velocity is same as the nozzle exit velocity. This zone is potential core of the jet.

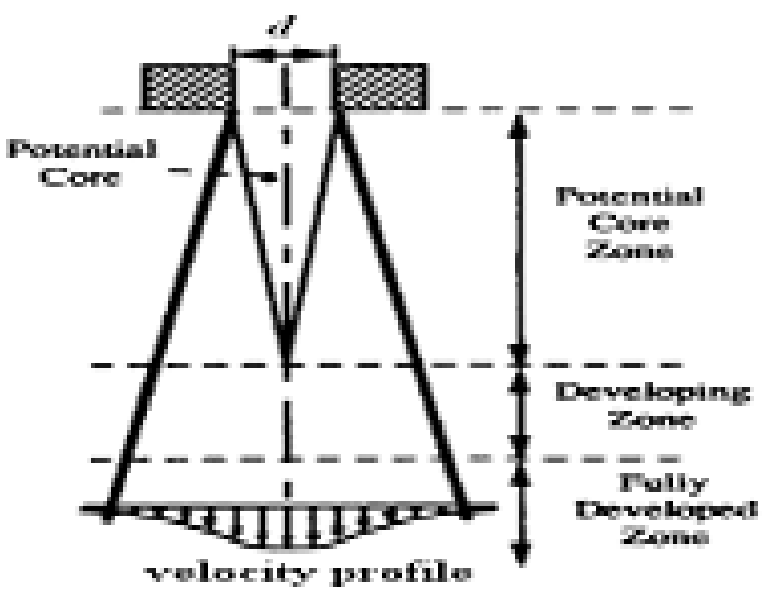

Fig.-1. Impinging jet

In the potential core zone, the centerline velocity of the jet remains constant and is equal to the nozzle exit velocity. The end of the potential core is defined as the axial distance from the nozzle exit up to the point where the jet velocity is 0.95 times the nozzle exit velocity (Jambunathan et al., 1992). Typical length of the potential core is found to be 6-7 times the nozzle diameter for the axis-symmetric jet and $4.7-7.7$ 
times the slot width for two dimensional jets (Viskanta, 1993). However, this length depends on nozzle geometry and turbulent intensity in the nozzle exit and initial velocity profile. In the developing zone, due to large shear stresses at the jet boundary, axial velocity profile decays. In the developed zone the velocity profile is fully developed and the jet broadens linearly along with linear decay of axial velocity.

\subsection{Structure of Impinging Jet}

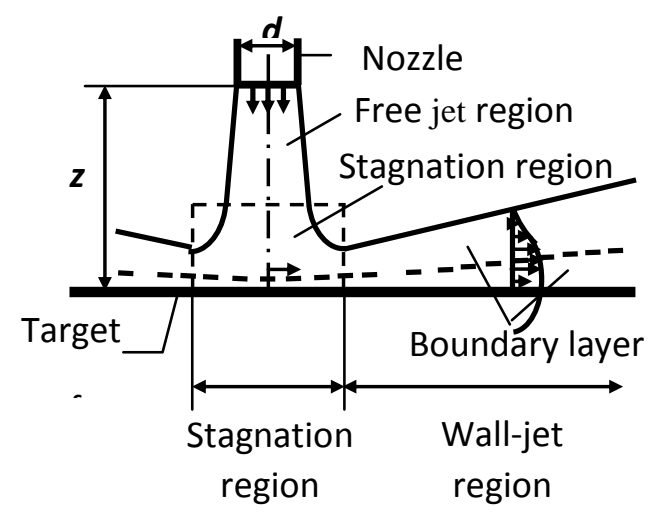

Fig.-2. Impinging jet

Unconfined jet impingement system is one in which jet after impingement on a surface is exited without confinement. Figure $1.5 \mathrm{~b}$ shows the flow field of an impinging jet on to an orthogonal plate. The flow structures of impinging axisymmetric jet can be subdivided into three characteristic regions.

1. The free jet region

2. The stagnation flow region

3. The wall jet region.

\section{EXPERIMENTAL SET UP}

Fig-3.shows a schematic of the experimental apparatus. Air is discharged from a long pipe nozzle which is mounted with its axis horizontal in the center of a confined plate. The air is supplied to the nozzle by means of a centrifugal blower mounted beside the confined plate. The air flow is regulated by a valve. The nozzle is $16.5 \mathrm{~mm}$ diameter and $750 \mathrm{~mm}$ length, of which outlet is slightly rounded. The impingement plate made of Plexiglas with area of $250 \mathrm{~mm}^{2}$ and $10 \mathrm{~mm}$ thickness, and it is mounted perpendicular to the jet axis. The jet issuing from the nozzle, with a velocity $\mathrm{U}_{0}$, impinges onto the impingement plate at a distance $\mathrm{H}$ from the nozzle and enters the surrounding room air.

The pressure measurements at the impingement surface were made for the nozzle-plate spacing's of $0.25-4$ for different Reynolds numbers lying the range of 20,000 to 40,000 . The pressure distributions at the impingement surface were obtained by moving the impingement plate with respect to the jet, using a traversing unit with an accuracy of $0.1 \mathrm{~mm}$. The surface pressures were measured with a pressure tapping 0.5 $\mathrm{mm}$ placed at the center of the impingement plate. This tapping was connected to a single column manometer to determine the surface pressures. The Reynolds number depends on the nozzle diameter, D, and the nozzle exit velocity, $\mathrm{U}_{0}$. The pressure coefficient, $\mathrm{Cp}$, is defined as $\mathrm{C}_{\mathrm{p}}=\Delta \mathrm{p} / 0.5 \rho \mathrm{V}^{2}{ }_{\mathrm{j}}$ where $\Delta \mathrm{p}$ represents the difference between the local pressure on the impingement surface and the atmospheric pressure while $V_{j}$ represent the jet velocity

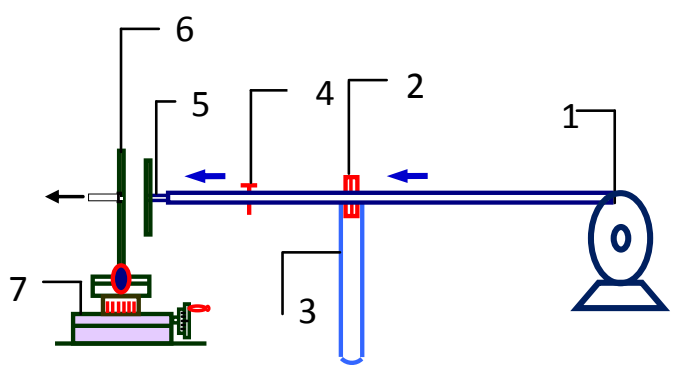

Fig.3. Layout of Experimental set-up

1) Air Blower.

2) Orifice flow-meter.

3) Differential manometer.

4) Flow control valve.

5) Nozzle.

6) Impingement plate assembly.

7) Traverse system

\section{RESULTS\&DISCUSSION}

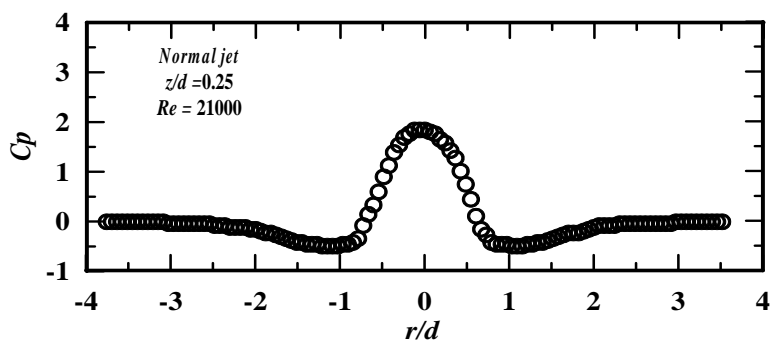

The radial distributions of the pressure coefficient

Fig $-\mathbf{3}(\mathrm{a}) \mathrm{z} / \mathrm{d}=0.25, \mathrm{Re}=21000$

The fig illustrates the variation of Pressure coefficient with the variation in $\mathrm{r} / \mathrm{d}$ ratio. The fig clearly reveals that the pressure coefficient is maximum at the stagnation point i.e. at $\mathrm{r} / \mathrm{d}=0$ and it decreases with increase in $\mathrm{r} / \mathrm{d}$ ratio. The Pressure coefficient at the stagnation point is 1.845 and it becomes zero nearly at $\mathrm{r} / \mathrm{d}=0.7$ the pressure coefficient was observed to become sub atmospheric at $\mathrm{r} / \mathrm{d}=0.72$ and reach a minimum at $r / d=1.03$, and from then increases to ambient at $r / d=2.8$. Pressure recovery is inevitable since momentum must be conserved. 


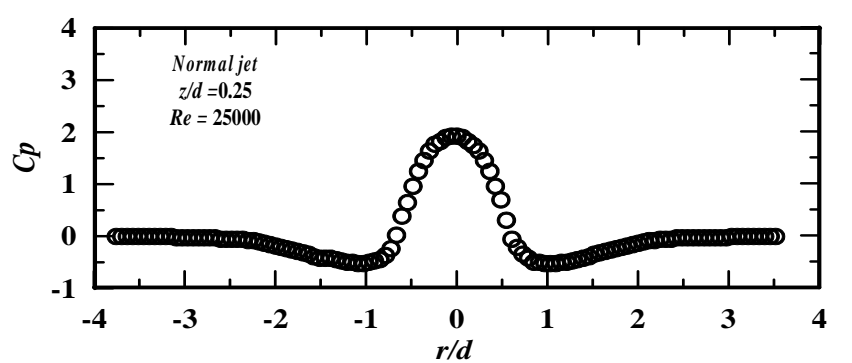

Fig.-3 (b) .z/d=0.25, $\operatorname{Re}=25000$

The above fig reveals that the pressure coefficient is maximum at the stagnation point and it decreases with increase in $\mathrm{r} / \mathrm{d}$ ratio. The Pressure coefficient at the stagnation point is 1.929 and it becomes zero nearly at $\mathrm{r} / \mathrm{d}=0.6$ the pressure coefficient was observed to become sub atmospheric at $\mathrm{r} / \mathrm{d}=0.67$ and reach a minimum at $r / d=1.1$, and from then increases to ambient at $r / d=2.66$. Pressure recovery is inevitable since momentum must be conserved.

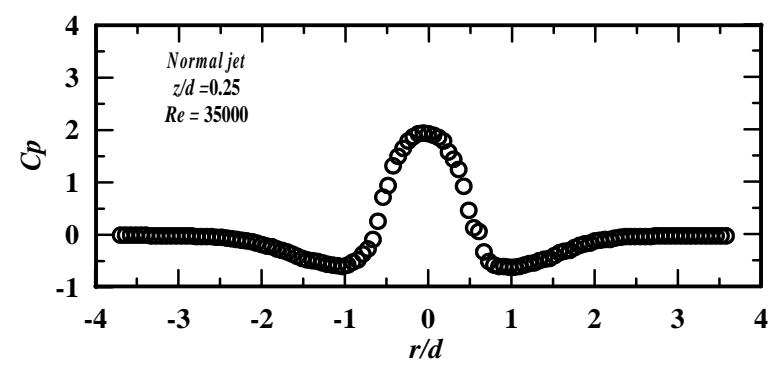

Fig.-3(c) $\mathrm{z} / \mathrm{d}=0.25, \mathrm{Re}=35000$

The Pressure coefficient at the stagnation point is 1.948 and it becomes zero nearly at $\mathrm{r} / \mathrm{d}=0.6$ the pressure coefficient was observed to become sub atmospheric at $\mathrm{r} / \mathrm{d}=0.66$ and reach a minimum at $r / d=1.03$, and from then increases to ambient at $r / d=2.72$. Pressure recovery is inevitable since momentum must be conserved.

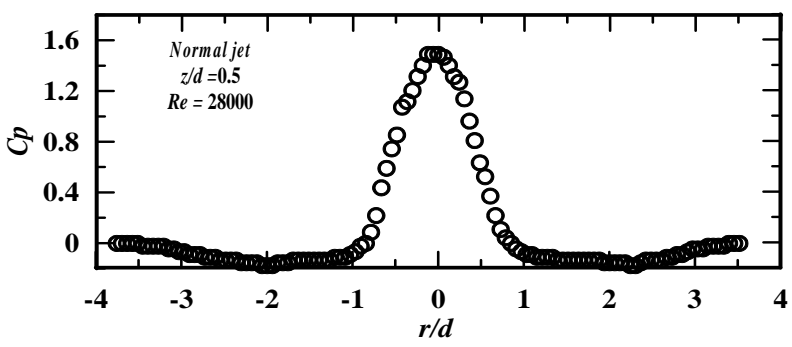

Fig-3 (a) $z / d=0.5, \operatorname{Re}=28000$

The fig illustrates the variation of Pressure coefficient with the variation in $\mathrm{r} / \mathrm{d}$ ratio. The fig clearly reveals that the pressure coefficient is maximum at the stagnation point i.e. at $r / d=0$ and it decreases with increase in $\mathrm{r} / \mathrm{d}$ ratio. The Pressure coefficient at the stagnation point is 1.49 and it becomes zero nearly at $\mathrm{r} / \mathrm{d}=0.80$, the pressure coefficient was observed to become sub atmospheric at $\mathrm{r} / \mathrm{d}=0.92$ and reach a minimum at $r / d=2.25$, and from then increases to ambient at $r / d=3.2$. Pressure recovery is inevitable since momentum must be conserved

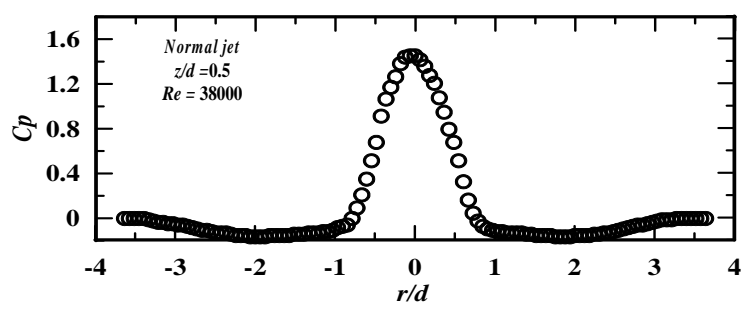

Fig.-3 (b) $\mathrm{z} / \mathrm{d}=0.5, \mathrm{Re}=38000$.

The above fig reveals that the pressure coefficient is maximum at the stagnation point and it decreases with increase in $\mathrm{r} / \mathrm{d}$ ratio. The Pressure coefficient at the stagnation point is 1.45 and it becomes zero nearly at $\mathrm{r} / \mathrm{d}=0.78$ the pressure coefficient was observed to become sub atmospheric at $\mathrm{r} / \mathrm{d}=0.84$ and reach a minimum at $r / d=1.9$, and from then increases to ambient at $r / d=3.1$. Pressure recovery is inevitable since momentum must be conserved.

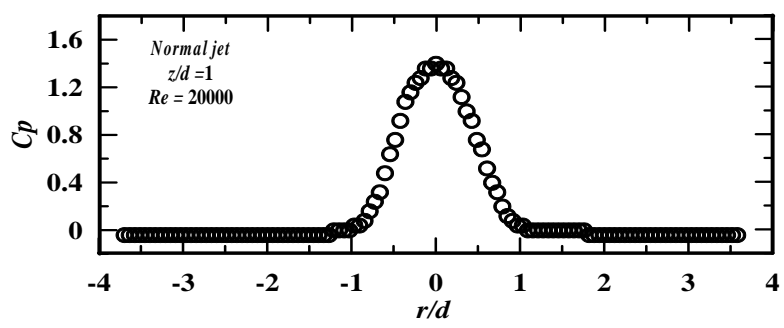

Fig.-3 (a) $\mathrm{z} / \mathrm{d}=1, \mathrm{Re}=20000$

The fig illustrates the variation of Pressure coefficient with the variation in $\mathrm{r} / \mathrm{d}$ ratio. The fig clearly reveals that the pressure coefficient is maximum at the stagnation point i.e. at $\mathrm{r} / \mathrm{d}=0$ and it decreases with increase in $\mathrm{r} / \mathrm{d}$ ratio. The Pressure coefficient at the stagnation point is 1.4 and it becomes zero nearly at $\mathrm{r} / \mathrm{d}=1.03$, the pressure coefficient was observed to become sub atmospheric at $\mathrm{r} / \mathrm{d}=1.81$, for further increase in $\mathrm{r} / \mathrm{d}$ there is no significant change in pressure coefficient.

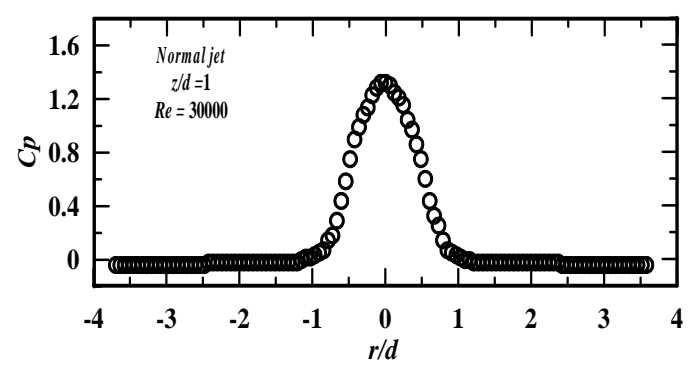

Fig.-3 (b) .z/d=1, Re=30000 
The above fig reveals that the pressure coefficient is maximum at the stagnation point and it decreases with increase in $\mathrm{r} / \mathrm{d}$ ratio. The Pressure coefficient at the stagnation point is 1.32 and it becomes zero nearly at $\mathrm{r} / \mathrm{d}=1.15$ the pressure coefficient was observed to become sub atmospheric at $\mathrm{r} / \mathrm{d}=1.21$ and reach a minimum at $r / d=2.45$ for further increase in $\mathrm{r} / \mathrm{d}$ there is no significant change in pressure coefficient.

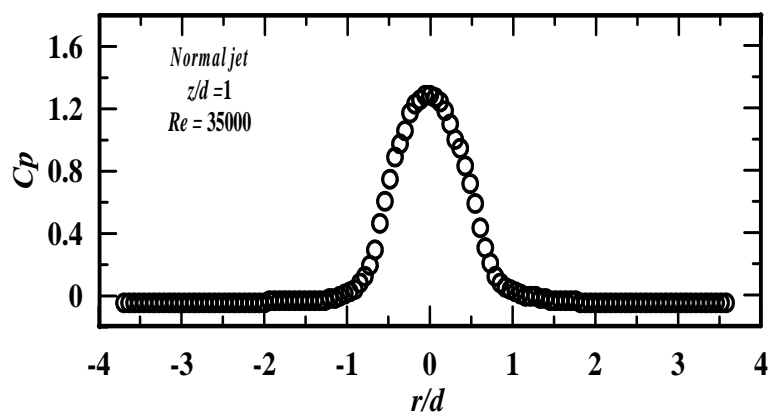

Fig.-3 (c) $z / d=1, R e=35000$

The above fig reveals that the pressure coefficient is maximum at the stagnation point and it decreases with increase in $\mathrm{r} / \mathrm{d}$ ratio. The Pressure coefficient at the stagnation point is 1.28 and it becomes zero nearly at $\mathrm{r} / \mathrm{d}=1.09$, the pressure coefficient was observed to become sub atmospheric at $\mathrm{r} / \mathrm{d}=1.33$ and reach a minimum at $r / d=1.9$, for further increase in $\mathrm{r} / \mathrm{d}$ there is no significant change in pressure coefficient

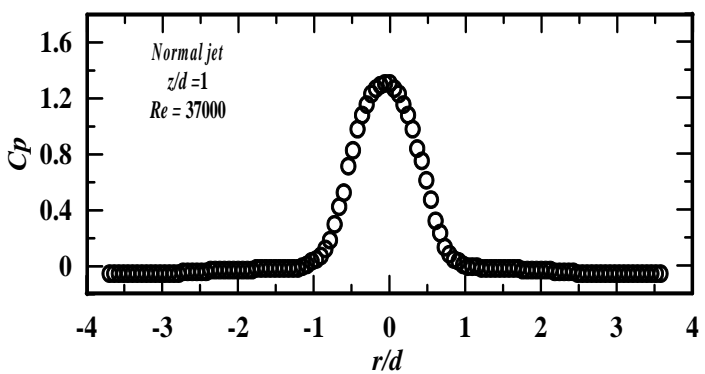

Fig-3(d) $z / d=1, R e=37000$

The above fig reveals that the pressure coefficient is maximum at the stagnation point and it decreases with increase in $\mathrm{r} / \mathrm{d}$ ratio. The Pressure coefficient at the stagnation point is 1.309 and it becomes zero nearly at $\mathrm{r} / \mathrm{d}=1.03$, the pressure coefficient was observed to become sub atmospheric at $\mathrm{r} / \mathrm{d}=1.21$ and reach a minimum at $r / d=2.48$, for further increase in $\mathrm{r} / \mathrm{d}$ there is no significant change in pressure coefficient

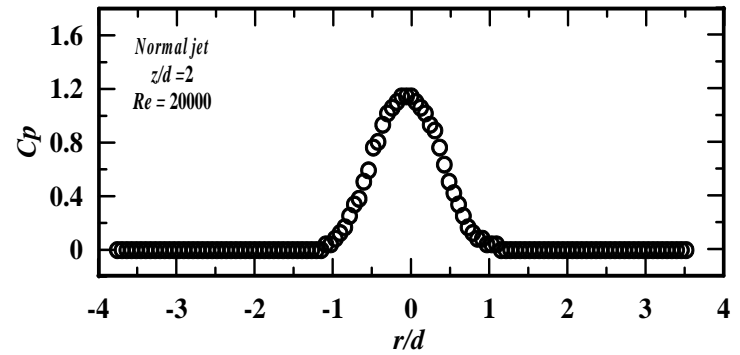

Fig - 3(a) $\mathrm{z} / \mathrm{d}=2, \mathrm{Re}=20000$

The fig illustrates the variation of Pressure coefficient with the variation in $\mathrm{r} / \mathrm{d}$ ratio. The fig clearly reveals that the pressure coefficient is maximum at the stagnation point i.e. at $\mathrm{r} / \mathrm{d}=0$ and it decreases with increase in $\mathrm{r} / \mathrm{d}$ ratio. The Pressure coefficient at the stagnation point is 1.14 and it becomes zero nearly at $\mathrm{r} / \mathrm{d}=1.09$ the pressure coefficient was observed to become sub atmospheric at $\mathrm{r} / \mathrm{d}=0.72$ and reach a minimum at $r / d=1.09$, and from then increases to ambient at $r / d=1.2$. Pressure recovery is inevitable since momentum must be conserved.

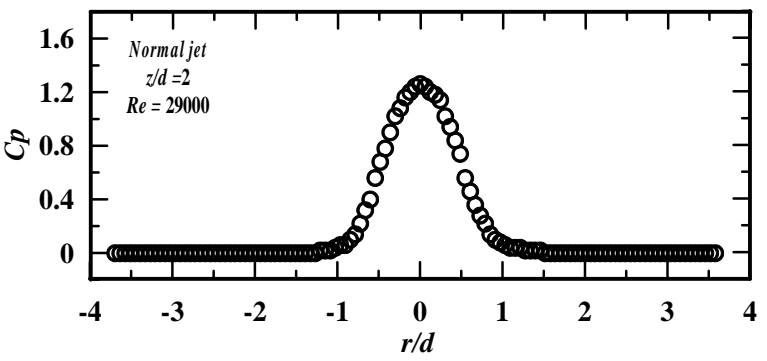

Fig.-3 (b) z/d=2, Re=29000

The Pressure coefficient at the stagnation point is 1.26 and it becomes zero nearly at $\mathrm{r} / \mathrm{d}=1.3$ the pressure coefficient was observed to become sub atmospheric at $\mathrm{r} / \mathrm{d}=0.67$ and reach a minimum at $r / d=1.3$, and from then increases to ambient at $r / d=1.5$. Pressure recovery is inevitable since momentum must be conserved.

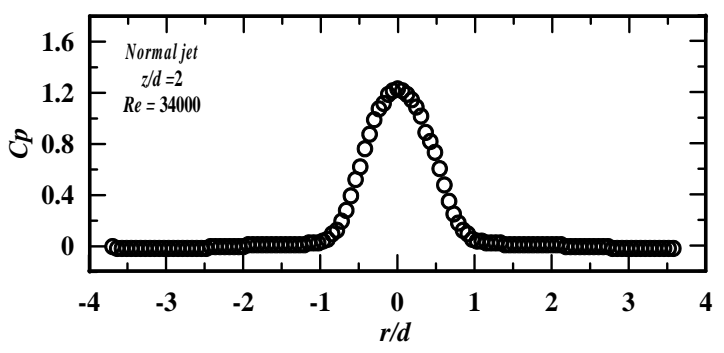

Fig.-3 (c) $\mathrm{z} / \mathrm{d}=2, \operatorname{Re}=34000$

The Pressure coefficient at the stagnation point is 1.23 and it becomes zero nearly at $\mathrm{r} / \mathrm{d}=2.4$ the pressure coefficient was observed to become sub atmospheric at $\mathrm{r} / \mathrm{d}=0.67$ and reach a minimum at $r / d=2.4$, and from then increases to ambient at 
$r / d=2.7$. Pressure recovery is inevitable since momentum must be conserved.

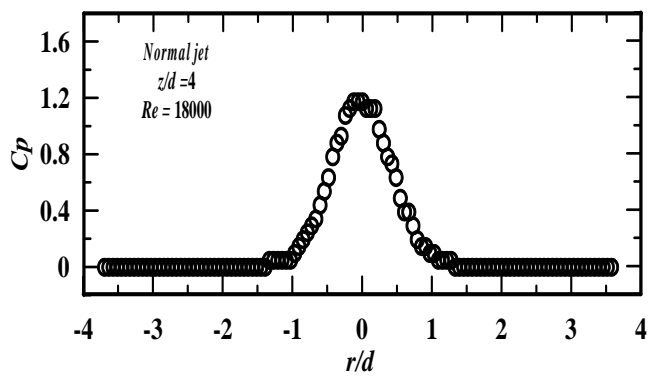

Fig-3 (a) $z / d=4, \operatorname{Re}=18000$

The fig illustrates the variation of Pressure coefficient with the variation in $\mathrm{r} / \mathrm{d}$ ratio. The fig clearly reveals that the pressure coefficient is maximum at the stagnation point i.e. at $\mathrm{r} / \mathrm{d}=0$ and it decreases with increase in $\mathrm{r} / \mathrm{d}$ ratio. The Pressure coefficient at the stagnation point is 1.17 and it becomes zero nearly at $\mathrm{r} / \mathrm{d}=1.3$, for further increase in $\mathrm{r} / \mathrm{d}$ ratio there is no significant changes in pressure coefficient.

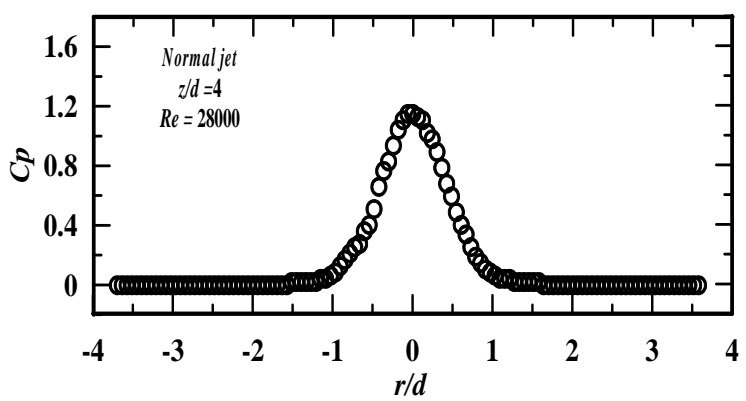

Fig.3 (b) $\mathrm{z} / \mathrm{d}=4, \mathrm{Re}=28000$

The Pressure coefficient at the stagnation point is 1.15 and it becomes zero nearly at $\mathrm{r} / \mathrm{d}=1.21$, for further increase in $\mathrm{r} / \mathrm{d}$ ratio there is no significant changes in pressure coefficient.

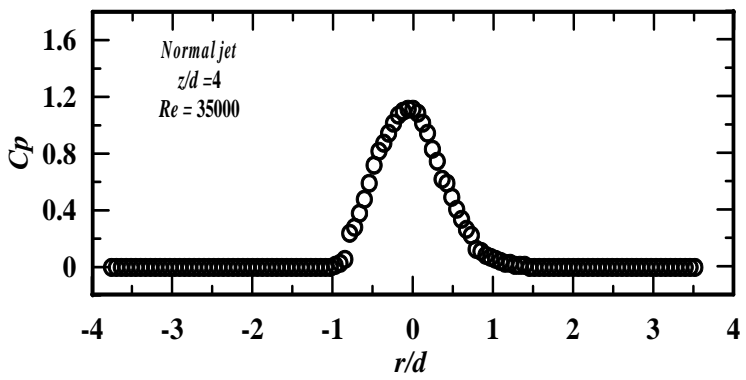

Fig.-3(c) $z / d=4, \operatorname{Re}=35000$

The Pressure coefficient at the stagnation point is 1.115 and it becomes zero nearly at $\mathrm{r} / \mathrm{d}=1.33$, for further increase in $\mathrm{r} / \mathrm{d}$ ratio there is no significant changes in pressure coefficient.

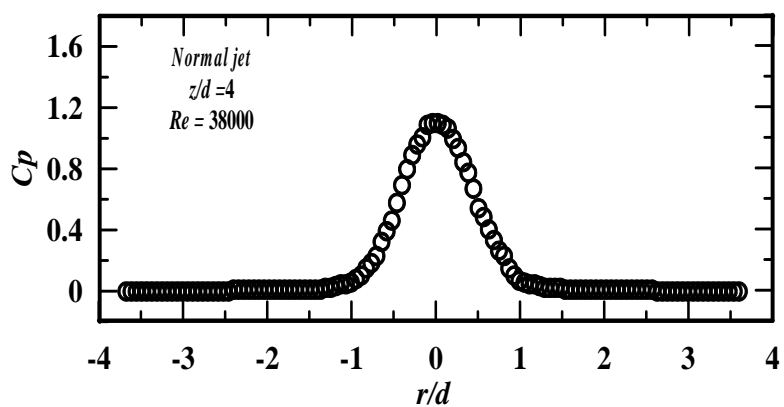

Fig.-3 (d) $\mathrm{z} / \mathrm{d}=4, \mathrm{Re}=38000$.

The Pressure coefficient at the stagnation point is 1.10 and it becomes zero nearly at $\mathrm{r} / \mathrm{d}=1.59$, for further increase in $\mathrm{r} / \mathrm{d}$ ratio there is no significant changes in pressure coefficient.

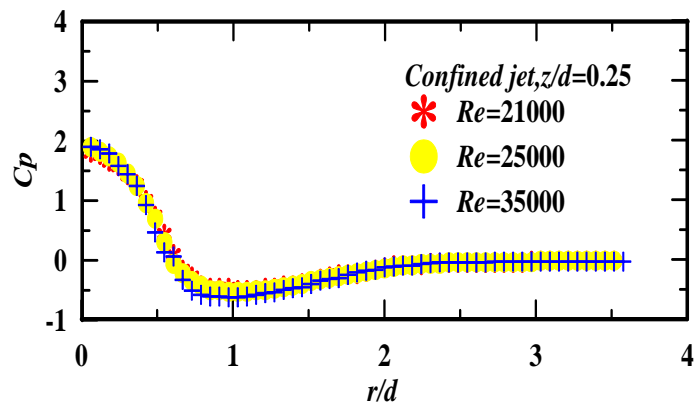

Fig- 4 (a) .Effect of the r/d ratio on pressure distribution in confined jet for $\mathrm{z} / \mathrm{d}=0.25$

The above fig illustrates the variation of Pressure coefficient with the variation in $\mathrm{r} / \mathrm{d}$ ratio for $\mathrm{z} / \mathrm{d}=0.25$. The fig clearly reveals that the pressure coefficient is maximum at the stagnation point i.e. at $\mathrm{r} / \mathrm{d}=0$ and it decreases with increase in $\mathrm{r} / \mathrm{d}$ ratio. From the fig it is clear that there is no significant change in the pressure coefficient with variation in the Reynolds number. The Pressure coefficient at the stagnation point is 1.9 and it becomes zero nearly at $\mathrm{r} / \mathrm{d}=0.65$ the pressure coefficient was observed to become sub atmospheric at $\mathrm{r} / \mathrm{d}$ $=0.66$ and reach a minimum at $r / d=1.03$, and from then increases to ambient at $r / d=2.8$. Pressure recovery is inevitable since momentum must be conserved.

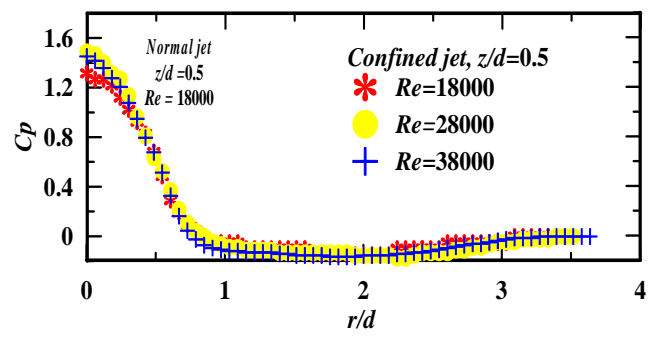

Fig.-4 (b) .Effect of the r/d ratio on pressure distribution in confined jet for $\mathrm{z} / \mathrm{d}=0.5$ 
The above fig illustrates the variation of Pressure coefficient with the variation in $\mathrm{r} / \mathrm{d}$ ratio for $\mathrm{z} / \mathrm{d}=0.5$. The fig clearly reveals that the pressure coefficient is maximum at the stagnation point i.e. at $\mathrm{r} / \mathrm{d}=0$ and it decreases with increase in $\mathrm{r} / \mathrm{d}$ ratio. From the fig it is clear that there is no significant change in the pressure coefficient with variation in the Reynolds number. The Pressure coefficient at the stagnation point is 1.45 and it becomes zero nearly at $\mathrm{r} / \mathrm{d}=0.65$ the pressure coefficient was observed to become sub atmospheric at $\mathrm{r} / \mathrm{d}=0.88$ and reach a minimum at $r / d=1.98$, and from then increases to ambient at $r / d=3.1$. Pressure recovery is inevitable since momentum must be conserved.

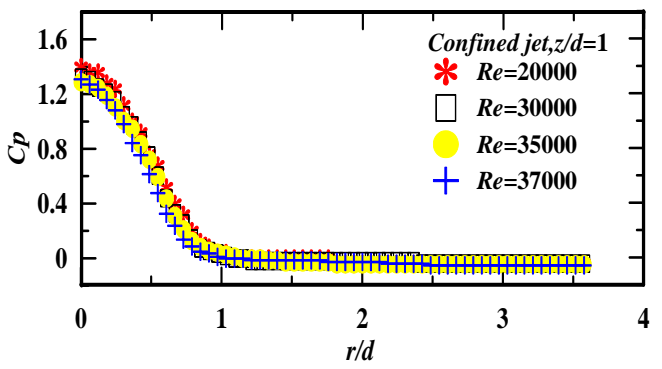

Fig-4 (c) Effect of the r/d ratio on pressure distribution in confined jet for $\mathrm{z} / \mathrm{d}=1$

The fig illustrates the variation of Pressure coefficient with the variation in $\mathrm{r} / \mathrm{d}$ ratio for $\mathrm{z} / \mathrm{d}=1.0$. The fig clearly reveals that the pressure coefficient is maximum at the stagnation point i.e. at $\mathrm{r} / \mathrm{d}=0$ and it decreases with increase in $\mathrm{r} / \mathrm{d}$ ratio. From the fig it is clear that there is no significant change in the pressure coefficient with variation in the Reynolds number. The Pressure coefficient at the stagnation point is 1.29 and it becomes zero nearly at $\mathrm{r} / \mathrm{d}=1.1$ the pressure coefficient was observed to become sub atmospheric at $\mathrm{r} / \mathrm{d}=1.21$ and reach a minimum at $r / d=2.2$, for further increase in $\mathrm{r} / \mathrm{d}$ there is no significant change in pressure coefficient.

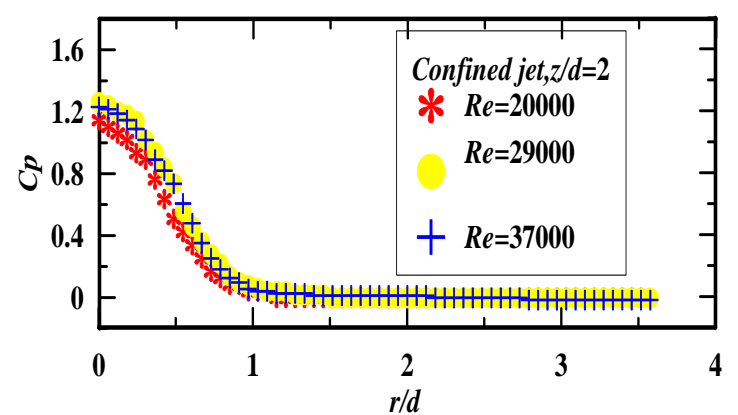

Fig.-4 (d) .Effect of the r/d ratio on pressure distribution in confined jet for $\mathrm{z} / \mathrm{d}=2$

The fig illustrates the variation of Pressure coefficient with the variation in $\mathrm{r} / \mathrm{d}$ ratio for $\mathrm{z} / \mathrm{d}=1.0$. The fig clearly reveals that the pressure coefficient is maximum at the stagnation point i.e. at $\mathrm{r} / \mathrm{d}=0$ and it decreases with increase in $\mathrm{r} / \mathrm{d}$ ratio. From the fig it is clear that there is no significant change in the pressure coefficient with variation in the Reynolds number. The Pressure coefficient at the stagnation point is 1.29 and it becomes zero nearly at $\mathrm{r} / \mathrm{d}=1.1$ the pressure coefficient was observed to become sub atmospheric at $\mathrm{r} / \mathrm{d}=1.21$ and reach a minimum at $r / d=2.2$, for further increase in $\mathrm{r} / \mathrm{d}$ there is no significant change in pressure coefficient.

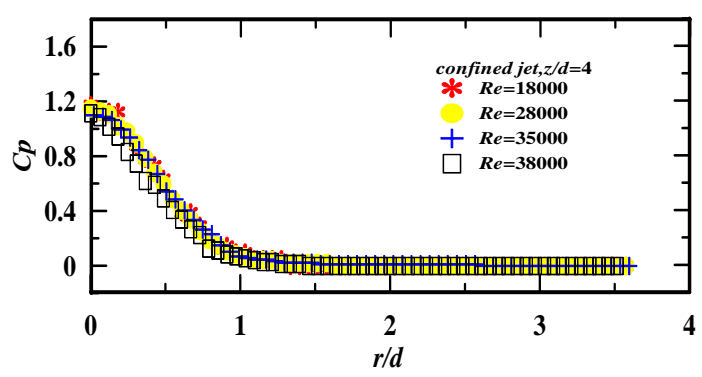

Fig.-4 (e) .Effect of the r/d ratio on pressure distribution in confined jet for $\mathrm{z} / \mathrm{d}=4$

The fig illustrates the variation of Pressure coefficient with the variation in $\mathrm{r} / \mathrm{d}$ ratio for $\mathrm{z} / \mathrm{d}=4$. The fig clearly reveals that the pressure coefficient is maximum at the stagnation point i.e. at $\mathrm{r} / \mathrm{d}=0$ and it decreases with increase in $\mathrm{r} / \mathrm{d}$ ratio. From the fig it is clear that there is no significant change in the pressure coefficient with variation in the Reynolds number. The Pressure coefficient at the stagnation point is 1.13 and it becomes zero nearly at $\mathrm{r} / \mathrm{d}=1.33$, for further increase in $\mathrm{r} / \mathrm{d}$ there is no significant change in pressure coefficient.

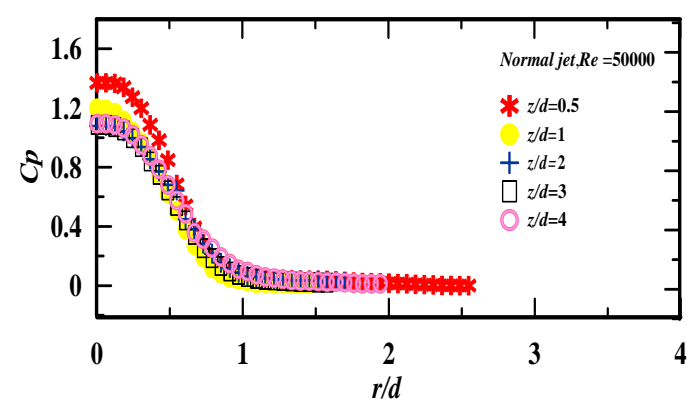

Fig.-4 (f) .Effect of the nozzle-to-plate spacing on pressure distribution in unconfined jet a $\mathrm{Re}=50,000$,

The fig illustrates the variation of Pressure coefficient with the variation in r/d ratio for a Reynolds number of 50000. The fig clearly reveals that the pressure coefficient is maximum for $\mathrm{z} / \mathrm{d}=0.5$ at the stagnation point i.e. at $\mathrm{r} / \mathrm{d}=0$ and it decreases with increase in r/d ratio. From the fig it is also clear that for all other $\mathrm{z} / \mathrm{d}$ ratios there is no significant change in the pressure coefficient. The pressure coefficient becomes zero at $\mathrm{r} / \mathrm{d}=1.27$, for further increase in $\mathrm{r} / \mathrm{d}$ ratio there is no significant change in pressure coefficient. 


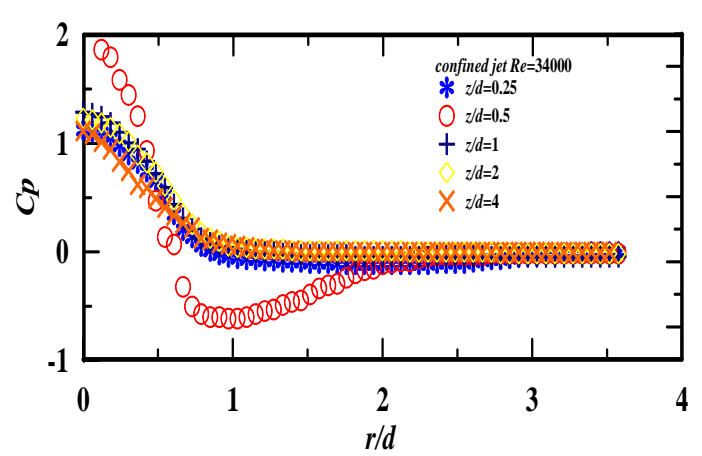

Fig.-4 (g) .Effect of the nozzle-to-plate spacing on pressure distribution in confined jet a $\operatorname{Re}=34,000$,

The above figure clearly reveals that the pressure coefficient is maximum at the stagnation point and decreases with increase in $\mathrm{r} / \mathrm{d}$ ratio. It is found that the pressure coefficient is maximum i.e. 1.948 for $\mathrm{z} / \mathrm{d}=0.25$ at the stagnation point. The pressure becomes sub atmospheric at approximately $\mathrm{r} / \mathrm{d}=0.66$ and then approaches to atmospheric value at $\mathrm{r} / \mathrm{d}=2.72$. For $\mathrm{z} / \mathrm{d}$ ratio of 0.5 , the Pressure coefficient at the stagnation point is 1.28 , the pressure coefficient was observed to become sub atmospheric at $\mathrm{r} / \mathrm{d}=1.33$ and reach a minimum at $r / d=1.9$, for further increase in $\mathrm{r} / \mathrm{d}$ there is no significant change in pressure coefficient. For $\mathrm{z} / \mathrm{d}$ ratios of 2 and 4 it is found that pressure coefficient

\section{CONCLUSIONS}

Experimental investigations were carried out on the impinging jet flow for Reynolds numbers up to 40,000 at various nozzleto-plate spacing's for confined configuration. The characteristics of an impinging circular jet region were found to be sensitive to the nozzle-to-plate spacing. The sub atmospheric regions which become stronger with increasing Reynolds number and decreasing nozzle-to plate spacing support the evidence of the recirculation zones. For unconfined jet, no sub atmospheric region is observed on the impingement surface for all the examined Reynolds numbers and spacing's.

The effect of the nozzle-to-plate spacing on the local surface pressure distributions is studied for confined jets. It is seen that, the pressure distributions are independent of the Reynolds number and depend on nozzle-to-plate spacing only. The maximum pressure occurs at the stagnation point $(\mathrm{r} / \mathrm{d}=0)$ for the all nozzle-to-plate spacing's studied and as $\mathrm{r} / \mathrm{d}$ increases, the pressure decreases. At very low spacing $(\mathrm{z} / \mathrm{d}=0.25)$ stagnation pressure is rather larger than those of the other spacing's due to rapidly decreasing of axial velocity in the deflection zone.

Figure a-e shows the pressure distributions of confined jet. For the spacing's up to $\mathrm{z} / \mathrm{d}=1$ and all the examined Reynolds numbers, a sub atmospheric region occurs. As the nozzle-to- plate spacing increases the fluid velocity decreases due to the jet spreading, and thus the sub atmospheric region expands in radial direction and its strength decreases.

Figure $\mathrm{f}$ shows the pressure distributions on impingement surface in unconfined jet. For Reynolds number of 50000, at very low spacing $(\mathrm{z} / \mathrm{d}=0.5)$ stagnation pressure is rather larger than those of the other spacing's due to rapidly decreasing of axial velocity in the deflection zone. In contrast to the confined jet, no sub atmospheric region is observed for the Reynolds number and the spacing's studied. This situation can be explained with the fluid velocity along the impingement surface is lower with respect to the confined jet, due to no flow confinement.

\section{REFERENCES}

[1]. Baydar E (1999) Confined impinging air jet at low Reynolds Numbers. Exp. Thermal Fluid Sci 19:27-33

[2]. Baydar E, Ozmen Y (2005) an experimental and numerical Investigation on a confined impinging air jet at high Reynolds Numbers. Appl Thermal Eng 25:409-421

[3]. Ichimiya K, Yamada Y (2003) three dimensional heat transfer of a confined circular impinging jet with buoyancy effects.

[4]. ASME J Heat Transfer 125:250-256 Huber AM, Viskanta R (1994) Convective heat transfer to a Confined impinging array of air jets with spent air exits. ASME J Heat Transfer 116:570-576

[5]. Ashfort-Frost S, Jambunathan K, Whithney CF (1997) Heat Transfer from a flat plate to a turbulent axisymmetric impinging jet. Proc Inst Mech Eng 211:167-172

[6]. S. Ashfort-Frost, K. Jambunathan, Numerical prediction of semicon jet impingement and comparison with experimental data, Int. J. Numer. Methods Fluids 23 (1996) $295 \pm 306$.

[7]. Yang Z, Sarkar P, Hu H (2011) an experimental study of flow field around a high-rise building model in tornado-like winds. J Fluids Struct 27(4):471-486

[8]. Zhang Y, Sarkar PP, Hu H (2012) Experimental and numerical investigations on the flow characteristics of microburst-like winds. 50th AIAA aerospace sciences meeting including the new horizons forum and aerospace exposition 09-12 January 2012, Nashville, Tennessee, AIAA 20121197

[9]. Letchford CW, Chay MT (2002) Pressure distributions on a cube in asimulated thunderstorm downburst, part B: moving downburst observations. J Wind Eng Ind Aerodyn 90:733-753 [10]. Peterka JA, Hosoya N, Dodge S, Cochran L, Cermak JE (1998) Area average peak pressures in a gable roof vortex region. J Wind Eng Ind Aerodyn 77-78(1):205-215. 